\title{
Desa Mitra dalam Budidaya Tanaman Obat Keluarga Menuju Desa Cibiru Wetan sebagai Sentra Herbal
}

\author{
Fauzan Zein Mutaqqin ${ }^{1}$, Widhya Aligita ${ }^{2}$, Soni Muhsinin ${ }^{3}$, Dadang Juanda ${ }^{4}$, \\ Aiyi Asnawi ${ }^{5}$ \\ 1, 2,3,4 Sekolah Tinggi Farmasi Bandung, ${ }^{5}$ Institut Teknologi Bandung
}

\begin{tabular}{|c|c|}
\hline ARTICLE INFO & ABSTRACT \\
\hline $\begin{array}{l}\text { Article History: } \\
\text { Received 05.09.2018 } \\
\text { Received in revised } \\
\text { form 11.11.2018 } \\
\text { Accepted 30.11.2018 } \\
\text { Available online } \\
\text { 21.12.2018 }\end{array}$ & $\begin{array}{l}\text { The area of Cibiru Wetan Village is a farming area because besides the limited } \\
\text { water supply, the land is hilly. With the initiative and participation of women } \\
\text { farmer groups which had so many achievements and skills, it was necessary } \\
\text { to explore the potential that could provide a new icon for Cibiru Wetan } \\
\text { Village. The purpose of the activity was to socialize and practice the } \\
\text { cultivating of the medicinal plants carried out by a group of women farmers } \\
\text { with simple and effective technology and finally able to become a center of } \\
\text { dried herbs production. The method used in the cultivation program for } \\
\text { medicinal plants was divided into three stages. The first stage was to provide } \\
\text { material counseling on family medicinal plants including the understanding } \\
\text { of the benefits of the plant, the second stage was to provide an explanation or } \\
\text { training in planting family medicinal plants and the last stage or third stage } \\
\text { was to practice directly in planting these medicinal plants. The results } \\
\text { showed a positive understanding of both groups for both the socialization } \\
\text { and counseling stages as well as for the practice of medicinal plants } \\
\text { cultivation. It could be concluded, the partner village activities in medicinal } \\
\text { plants cultivation could improve the understanding of the target group. }\end{array}$ \\
\hline
\end{tabular}

DOI: $10.30653 / 002.201832 .59$

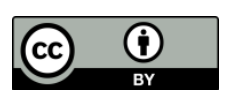

This is an open access article distributed under the terms of the Creative Commons Attribution 4.0 International License, which permits unrestricted use distribution, and reproduction in any medium, provided the original work is properly cited. (c) 2018 Fauzan Zein Mutaqqin, Widhya Aligita, Soni Muhsinin, Dadang Juanda, Aiyi Asnawi.

\section{PENDAHULUAN}

Tanaman obat keluarga (disingkat TOGA) adalah tanaman hasil budidaya rumahan yang berkhasiat sebagai obat. Taman obat keluarga pada hakekatnya adalah sebidang tanah, baik di halaman rumah, kebun ataupun ladang yang digunakan untuk membudidayakan tanaman yang berkhasiat sebagai obat dalam rangka memenuhi keperluan keluarga akan obat-obatan. Kebun tanaman obat atau bahan obat dan selanjutnya dapat disalurkan kepada masyarakat, khususnya obat yang berasal dari tumbuh-tumbuhan. Budidaya tanaman obat untuk keluarga (TOGA) dapat memacu 
usaha kecil dan menengah di bidang obat-obatan herbal sekalipun dilakukan secara individual. Setiap keluarga dapat membudidayakan tanaman obat secara mandiri dan memanfaatkannya, sehingga akan terwujud prinsip kemandirian dalam pengobatan keluarga (Sari, Yuniar, Siahaan, Riswati, \& Syaripuddin, 2015: 126).

Pemanfaatan tanaman sebagai obat-obatan di Indonesia juga telah berlangsung ribuan tahun yang lalu. Pada pertengahan abad ke XVII seorang botanikus bernama Jacobus Rontius (1592-1631) mengumumkan khasiat tumbuh-tumbuhan dalam bukunya De Indiae Untriusquere Naturali et Medica. Meskipun hanya 60 jenis tumbuh-tumbuhan yang diteliti, tetapi buku ini merupakan dasar dari penelitian tumbuh-tumbuhan obat oleh N.A. van Rheede tot Draakestein (1637-1691) dalam bukunya Hortus Indicus Malabaricus. Pada tahun 1888 didirikan Chemis Pharmacologisch Laboratorium sebagai bagian dari Kebun Raya Bogor dengan tujuan menyelidiki bahan-bahan atau zat-zat yang terdapat dalam tumbuh-tumbuhan yang dapat digunakan untuk obat-obatan (Sastrahidayat, 2016).

Salan (2009, p. 40) menyebut bahwa kecenderungan meningkatnya penggunaan obat tradisional didasari oleh beberapa faktor, yaitu: 1) Pada umumnya, harga obat-obatan buatan pabrik yang sangat mahal, sehingga masyarakat mencari alternatif pengobatan yang lebih murah; 2) Efek samping yang ditimbulkan oleh obat tradisional sangat kecil dibandingkan dengan obat buatan pabrik; dan 3) Kandungan unsur kimia yang terkandung di dalam obat tradisional sebenarnya menjadi dasar pengobatan kedokteran modern. Artinya, pembuatan obat-obatan pabrik menggunakan rumus kimia yang telah disentetis dari kandungan bahan alami ramuan tradisional.

Desa Cibiru Wetan adalah salah satu desa yang tergabung dalam Kecamatan Cileunyi, Kabupaten Bandung, Provinsi Jawa Barat. Secara geografis desa ini berada di kawasan Gunung Manglayang, dengan batas-batas: sebelah utara berbatasan dengan Gunung Manglayang itu sendiri; sebelah selatan berbatasan dengan Desa Cibiru Kulon; sebelah barat berbatasan dengan Desa Cibiru Wetan dan Desa Desa Cilengkrang; dan sebelah timur berbatasan dengan Desa Cimekar. Desa ini tidak hanya berada di kaki tapi juga di lereng gunung, sehingga wilayahnya tidak hanya berupa dataran rendah semata, tetapi juga dataran tinggi (berbukit-bukit) yang mendominasinya. Luas wilayah Desa Cibiru Wetan sebagian besar $(45,93 \%)$ berupa tegalan/ladang yang terbentang di sekitar puncak Gunung Manglayang, tepatnya di wilayah Kampung: Cikoneng I, II, III, dan Pamubusan. Wilayah perkampungan tersebut memang cocok untuk areal perladangan karena disamping persediaan air terbatas, tanahnya berbukit-bukit (Halimah, 2007).

Pemerintah Desa Cibiru Wetan membentuk Kelompok Wanita Tani (KWT) sebagai salah satu wadah bagi petani dimana para anggotanya terdiri dari para wanita-wanita yang bergerak dalam kegiatan pertanian. KWT berbeda dengan kelompok tani yang lainnya, dalam pembinaannya KWT diarahkan untuk mempunyai suatu usaha produktif dalam skala rumah tangga yang memanfaatkan atau mengolah hasil-hasil pertanian maupun perikanan (Arifin, 2003). Penduduk Desa Cibiru Wetan khususnya KWT (Kelompok Wanita Tani) merupakan KWT dengan tingkat partisipasi dalam kegiatan desa yang sangat tinggi. Hal ini telah dibuktikan dengan prestasi yang telah dicapai baik untuk tingkat lokal maupun nasional (Humas Pemkab Bandung, 2016). Disamping itu KWT telah menerima berbagai pelatihan dan sosialisasi antara lain membuat kompos, merajut, mengelola bisnis center. Dengan berbagai pelatihan dan sosialisasi yang diterima tetapi sampai sekarang KWT belum memiliki sesuatu usaha yang menjadi icon dari Desa Cibiru Wetan. 
Berdasarkan penjelasan di atas, maka diperlukan mengadakan kegiatan program desa mitra untuk mendesain Desa Cibiru Wetan menjadi sentra simplisia herbal. Dengan adanya program desa mitra, KWT-KWT yang ada akan dilatih keterampilan dalam memproduksi simplisia herbal. Tujuan khusus adalah sosialisasi dan praktek membudidayakan tanaman TOGA yang memiliki nilai ekonomis yang bagus dan dapat dilakukan oleh KWT dengan teknologi tepat guna yang sederhana. Diharapkan setiap rumah di Cibiru Wetan akan mampu menghasilkan bahan baku untuk simplisia herbal.

\section{METODE PELAKSANAAN}

Kelompok yang menjadi sasaran kegiatan ini adalah 2 Kelompok Wanita Tani (KWT) dan ibu PKK dalam Desa Cibiru Wetan. Jumlah orang secara keseluruhan adalah 30 orang yang dibagi menjadi tiga kelompok yaitu KWT I (KWT dalam area Desa Cibiru bagian atas), KWT II (KWT dalam area Desa Cibiru bagian bawah) dan kelompok PKK. Rata-rata pendidikan anggota kelompok sasaran adalah SMP. Pada umumnya ibu-ibu ini bekerja sebagai petani $(80 \%)$, sisanya mengurus rumah tangga dan dagang.

Metode pelaksanaan yang digunakan dalam program pelatihan penanaman tanaman obat ini dibagi menjadi tiga tahapan. Tahapan pertama adalah memberikan penyuluhan materi tentang tanaman obat keluarga mulai dari pengertian hingga manfaat dari tanaman tersebut, tahapan kedua adalah memberikan penjelasan atau pelatihan menanam tanaman obat keluarga dan tahapan terakhir atau tahapan ketiga adalah melakukan praktek secara langsung dalam menanam tanaman obat tersebut.

Kegiatan dilaksanakan per minggu untuk tiap topik/tahapan kegiatan. Kegiatan praktek difokuskan di lahan percontohan Desa Cibiru Wetan dan hasil praktek diterapkan langsung disetiap rumah anggota KWT yang terlibat. Diharapkan setiap rumah di Cibiru Wetan akan mampu menghasilkan bahan baku untuk simplisia herbal secara kontinu.

\section{HASIL DAN PEMBAHASAN}

Beberapa tanaman yang sering dibudidayakan oleh masyarakat antara lain jahe, dan stevia. Jahe (Zingiber officinale), adalah tanaman rimpang yang sangat populer sebagai rempah-rempah dan bahan obat (Setyawan, 2002: 48). Rimpangnya berbentuk jemari yang menggembung di ruas-ruas tengah. Rasa dominan pedas disebabkan senyawa keton bernama zingeron. Rimpang jahe, terutama yang dipanen pada umur yang masih muda tidak bertahan lama disimpan di gudang. Untuk itu diperlukan pengolahan secepatnya agar tetap layak dikonsumsi. Untuk mendapatkan rimpang jahe yang berkualitas, jahe dipanen pada umur tidak terlalu muda juga tidak terlalu tua (Setyaningrum \& Saparinto, 2013).

Stevia adalah genus dari sekitar 240 spesies dari ramuan dan semak dalam keluarga bunga matahari (Asteraceae), berasal dari daerah subtropis dan tropis dari barat Amerika Utara hingga Amerika Selatan (Geuns, 2003). Spesies Stevia rebaudiana, umumnya dikenal sebagai sweetleaf, daun manis, sugar leaf, atau hanya stevia, banyak ditanam sebagai daun manis. Sebagai pemanis dan gula pengganti, rasa stevia memiliki onset lambat dan durasi yang lebih lama daripada gula, dan beberapa ekstrak memiliki citarasa pahit atau licorice seperti aftertaste pada konsentrasi tinggi. Dengan sari steviol glikosida yang memiliki manis gula hingga 300 kali (Stones, 2011), stevia telah menarik perhatian dengan meningkatnya kebutuhan karbohidrat rendah, pemanis rendah-gula. Karena stevia memiliki efek yang dapat diabaikan pada glukosa darah yang menarik bagi orang-orang pada diet 
karbohidrat-dikendalikan. Maka dalam kegiatan ini difokuskan untuk membudidayakan tanaman jahe dan stevia.

\section{Sosialisasi dan Penyuluhan Budidaya}

Kegiatan sosialisasi ini yaitu pemberian materi tentang pengertian tanaman obat keluarga, manfaat dari tanaman, dan jenis produk simplisia herbal dilakukan selama dua hari. Penyuluhan hari pertama untuk KWT I dan KWT II dan hari kedua untuk Ibu PKK. Kegiatan ini berupa penyuluhan, diskusi dan tanya jawab. Hasil kegiatan menunjukkan peningkatan pemahaman dari kelompok sasaran tentang materi yang diberikan.

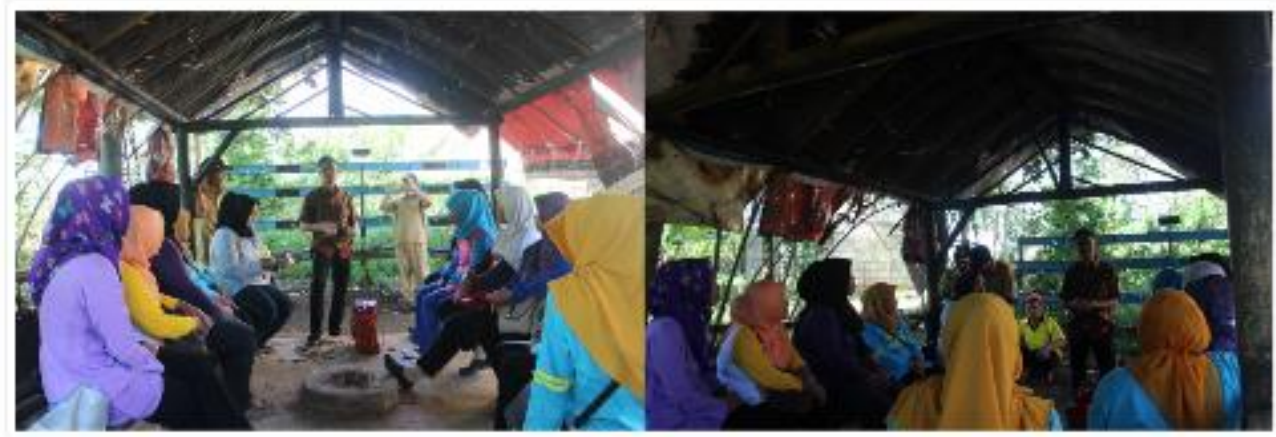

Gambar 1. Kegiatan Sosialisasi dan Penyuluhan Budidaya Toga

\section{Pemilihan Bibit}

Bibit berkualitas adalah bibit yang memenuhi syarat mutu genetik, mutu fisiologik (persentase tumbuh yang tinggi), dan mutu fisik (bibit yang bebas hama dan penyakit). Bahan bibit diambil langsung dari kebun (bukan dari pasar) dari tanaman yang sudah tua dan sehat. Sebaiknya bibit dikecambahkan terlebih dahulu. Penyemaian dapat dilakukan dengan peti kayu atau dengan bedengan.

Sebelum ditanam, bibit harus dibebaskan dari ancaman penyakit dengan cara bibit tersebut dimasukkan ke dalam karung dan dicelupkan ke dalam larutan fungisida sekitar 8 jam. Kemudian bibit dijemur 2-4 jam, barulah ditanam.

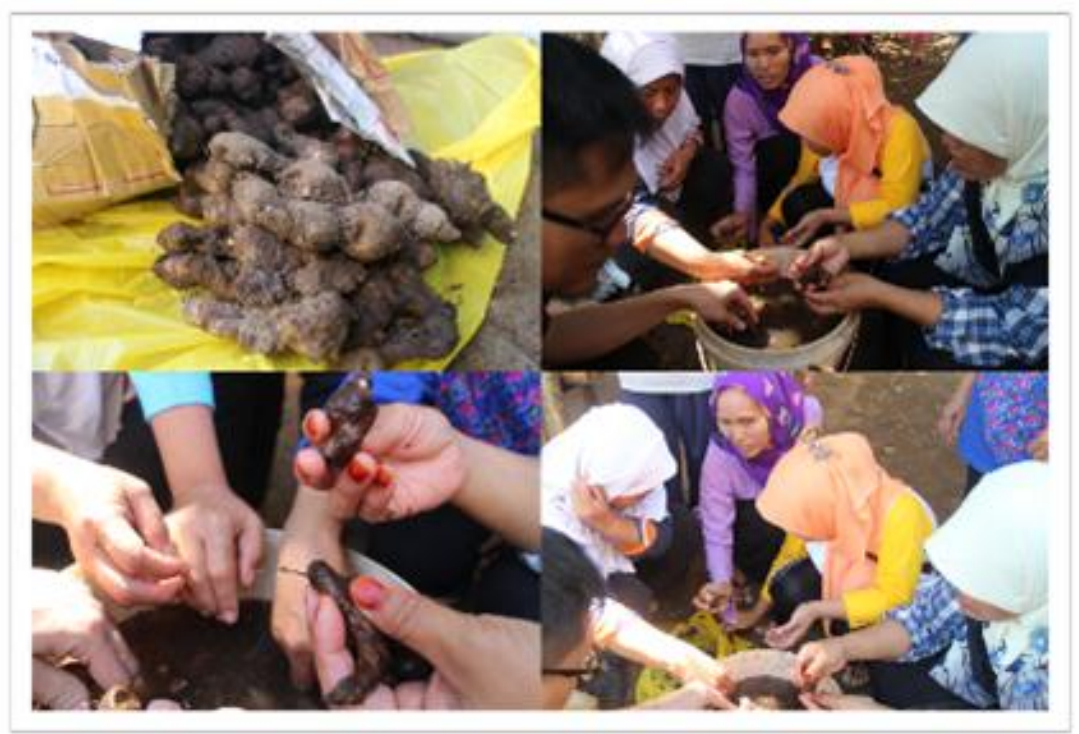

Gambar 2. Kegiatan Penyiapan dan Pemilihan Bibit 
Kegiatan ini berupa pemaparan, praktek, diskusi dan tanya jawab. Hasil kegiatan menunjukkan peningkatan pemahaman dari kedua KWT dan Ibu PKK tentang materi yang diberikan.

\section{Pengolahan Tanah}

Pengolahan tanah yang digunakan sebagai media dalam polybag atau pot, pada awalnya media tanah dibiarkan 2-4 minggu agar gas-gas beracun menguap serta bibit penyakit dan hama akan mati terkena sinar matahari. Sebelum ditanam media tanah di berikan pupuk kandang dan dolomit dan tanah.

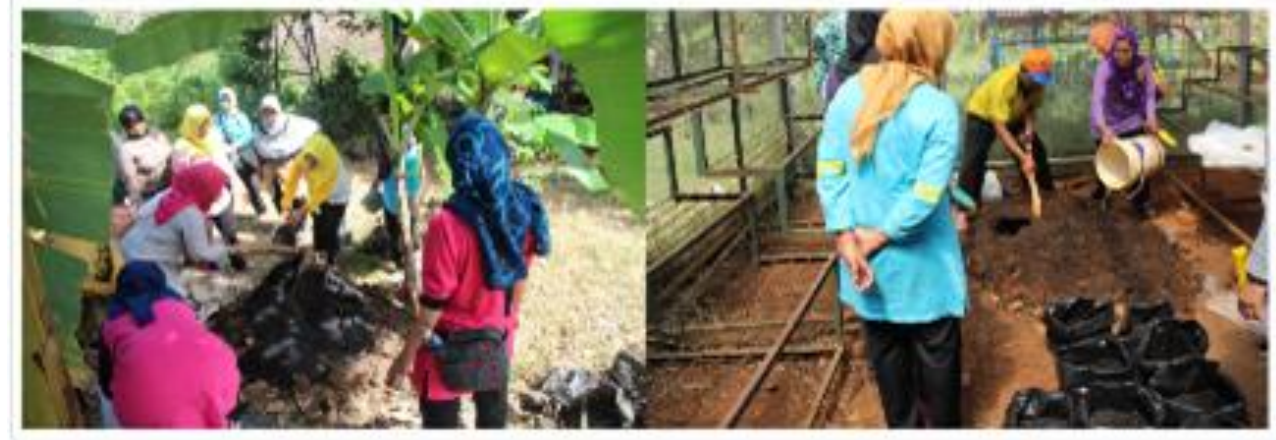

Gambar 3. Kegiatan Penyiapan Media Tanah untuk Polybag/Pot

Kegiatan ini berupa pemaparan, praktek, diskusi dan tanya jawab. Hasil kegiatan menunjukkan peningkatan pemahaman dari kedua KWT dan Ibu PKK tentang materi yang diberikan.

\section{Penanaman dan Pemeliharaan Tanaman}

Penanaman jahe sebaiknya dilakukan secara tumpangsari, dengan pertimbangan: mengurangi kerugian yang disebabkan naik turunnya harga, menekan biaya kerja, meningkatkan produktivitas lahan. memperbaiki sifat fisik tanah. Cara tanam dengan cara melekatkan bibit rimpang secara rebah ke dalam lubang tanam atau alur yang sudah disiapkan. Perioda Tanam tanam jahe sebaiknya pada awal musim hujan.

Pemeliharaan Tanaman dengan cara penyulaman dimana sekitar 2-3 minggu setelah tanam, bila ada rimpang yang mati segera lakukan penyulaman dan penyiangan yaitu penyiangan pertama dilakukan pada umur 2-4 minggu kemudian dilanjutkan 3-6 minggu sekali. Hal ini tergantung pada kondisi tanaman pengganggu yang tumbuh.

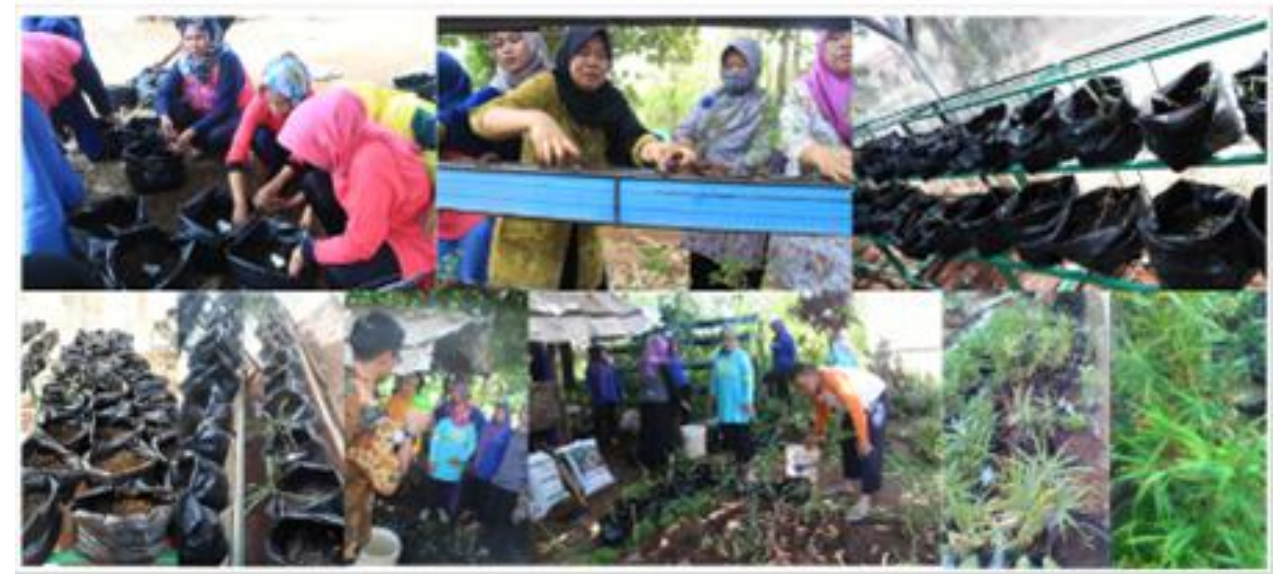

Gambar 4. Kegiatan Penanaman dan Pemeliharaan Tanaman 
Selain pupuk dasar (pada awal penanaman), tanaman perlu diberi pupuk susulan kedua (pada saat tanaman berumur 2-4 bulan). Pupuk dasar yang digunakan adalah pupuk organik. Pemupukan tahap kedua digunakan pupuk kandang dan pupuk buatan (urea 20 gram/pohon; TSP 10 gram/pohon; dan ZK (10 gram/pohon), serta $\mathrm{K}_{2} \mathrm{O}$ pada tanaman yang berumur 4 bulan (Rukmana, 2000).

Kegiatan ini berupa pemaparan, praktek, diskusi dan tanya jawab. Hasil kegiatan menunjukkan peningkatan pemahaman dari kedua KWT dan Ibu PKK tentang materi yang diberikan. Secara keseluruhan, tahapan kegiatan budidaya TOGA menunjukan peningkatan pemahaman dan ketrampilan dari peserta.

\section{SIMPULAN}

Kegiatan sosialisasi, penyuluhan, dan praktek budidaya TOGA pada Kelompok Wanita Tani di Desa Cibiru Wetan mampu meningkatkan pemahaman dan ketrampilan anggotanya dalam membudidayakan tanaman jahe dan stevia.

\section{REFERENSI}

Arifin, B. (2003). Pembangunan pertanian (Buku ajar). Lampung: Universitas Lampung.

Geuns, J. M. (2003). Stevioside. Phytochemistry, 64(5), 913-921.

Halimah, U. (2007). Desa Cibiru Wetan (2006). Retrieved November 11, 2018 from https://uun-halimah.blogspot.com/2007/12/desa-cibiru-wetan-2006.html.

Humas Pemkab Bandung. (2016). PKK Desa Cibiru Wetan siap wakili Jawa Barat. Retrieved November $\quad 11, \quad 2018$ from http://jabarprov.go.id/index.php/news/19582/PKK_Desa_Cibiru_Wetan_Siap_Waki li_Jawa_Barat.

Rukmana, I. H. R. (2000). Usaha tani jahe. Yogyakarta: Kanisius.

Salan, R. (2009). Penelitian faktor-faktor psiko-sosio-kultural dalam pengobatan tradisional pada tiga daerah, Palembang, Semarang, Bali. Jakarta: Balitbang Kesehatan, Pusat Penelitian Kanker dan Pengembangan Radiologi, Departemen Kesehatan RI.

Sari, I. D., Yuniar, Y., Siahaan, S., Riswati, R., \& Syaripuddin, M. (2015). Tradisi masyarakat dalam penanaman dan pemanfaatan tumbuhan obat lekat di pekarangan. Jurnal Kefarmasian Indonesia, 5(2), 123-132.

Sastrahidayat, I. R. (2016). Penyakit pada tumbuhan obat-obatan, rempah-bumbu dan stimulan. Malang: Universitas Brawijaya Press.

Setyaningrum, H. D., \& Saparinto, C. (2013). Jahe. Jakarta: Penebar Swadaya Grup.

Setyawan, A. D. (2002). Keragaman varietas jahe (Zingiber officinale Rosc.) berdasarkan kandungan kimia minyak atsiri. BioSMART: Journal of Biological Science, 4(2), 48-54.

Stones, M. (2011). Stevia wins final EU approval. Retrieved November 11, 2018 from http://www.foodmanufacture.co.uk/Ingredients/Stevia-wins-final-EU-approval. 